\title{
Mário Quintana: na opção do verso a força mágica da palavra
}

Sergio Alves Peixoto

UFMG

Resumo: O ensaio tem como objetivo definir a especificidade do projeto estético de Mário Quintana em relação às vertentes vanguardistas da poesia brasileira de seu tempo, especialmente o Concretismo, reafirmando a modernidade do lirismo de sua poesia.

Palavras-chave: poesia brasileira, concretismo, Mário Quintana.

Do poeta que traz em si o gérmen da divindade, como diz o romântico Novalis, ${ }^{1}$ ou, voltando mais atrás no tempo, do poeta que, segundo Platão, escreveria em estado de transe, dominado por uma força divina que "fala" através dele, ${ }^{2}$ chegamos, modernamente, ao poeta plenamente consciente do fazer poético como um árduo aprendizado, uma luta onde razão e emoção devem andar juntas. Momentos houve, porém, em que a razão foi considerada como única fonte do poema. Gerada pelo que Henri Bremond chama de "imperialismo antimístico", essa concepção

1. Cf. NOVALIS. Fragments, p. 65.

2. PLATÃO. Ion, p. 83.

3. BREMOND. La poésie pure, p. 27. 
tenta abolir, de uma vez por todas, essa coisa estranha que é a inspiração. O poeta nada mais seria do que um artífice que racionalmente trabalha a linguagem. $\mathrm{E}$, ainda hoje em dia, falar em inspiração é, muitas vezes, passar por ridículo, pois o racionalismo passou a ser o novo deus moderno em um mundo que se modifica a cada instante, onde a busca do novo, de uma nova arte que retrate fielmente essa nova humanidade se instaura como valor máximo. Nunca se escreveram tantos manifestos literários como a partir das vanguardas europeias do final do século XIX, início do século XX. Falar sobre poesia é, nesse momento, tão importante quanto fazê-la. O homem sente necessidade de transformar em raciocínio o que lhe brota em emoção. Tentar esconder a emoção, eis um dado característico da poesia de nosso tempo. Enquanto o poeta do século XIX não se envergonhava de mostrar seus sentimentos, o poeta moderno tenta escondê-los, dissimulá-los principalmente através de um sorriso cúmplice que busca trazer aos lábios do leitor. Em meio à efervescência do novo e ao domínio do racional, o poeta precisa mostrar "como fazer" e "o que é" a nova poesia que surge. E se quisermos estabelecer o primeiro momento em que a poesia passa a sofrer transformações realmente drásticas, teremos que, necessariamente, nos reportar ao Futurismo.

\section{Do verso à palavra}

É com o Futurismo de Marinetti que a poesia tradicional sofre o seu primeiro duro golpe. Os famosos manifestos futuristas (mais famosos do que a obra poética realizada por estes poetas) nos mostram como fazer a nova, moderna e revolucionária poesia: substituir os sinais gráficos tradicionais por símbolos matemáticos e musicais, abolir todo e qualquer índice de subjetivismo, pulverizar o verso a fim de que as palavras, agora soltas, passem a ocupar o espaço do verso, revelando novas formas antes jamais pensadas, dando à leitura do poema uma espécie de mimetismo capaz de recriar a velocidade emergente do século das máquinas. É com o Futurismo que começa a surgir, para a poesia, uma nova linguagem formal baseada essencialmente na força das palavras em liberdade. Os outros "ismos" do século XX, como o Dadaísmo e o Cubismo, não farão nada mais do que prosseguir as pesquisas futuristas no que tange à dissolução do verso. $O$ Surrealismo, tão importante até hoje, é o movimento que mais deles se afasta, pois além de ter dado maior importância ao mundo interior do artista, aos sonhos, e à própria loucura, manteve, como mostra Haroldo de Campos, uma linguagem poética ainda bastante tradicional: 
O Surrealismo, defrontando-se com a barreira da lógica tradicional, não procurou desenvolver uma linguagem que a superasse; ao contrário, instalou seu quartel-general no lado "maudit" da linguagem lógico-discursiva, onde se produzem "proposições admiráveis como: um bugio de cauda malhada não é uma assembleia constitucional". O "revólver de cabelos brancos", de Bréton, vige no rei do absurdo que se desencadeia da linguagem ordenada pelo sistema aristotélico, quando este é levado, como processo, às suas últimas consequências. É o reinado paradoxo, do "nonsense", cujo estatuto são as "confusões de níveis de abstrações". O surrealismo, embora insurja contra a lógica é apenas o filho bastardo desta.

No Brasil, os "ismos" europeus convergem para um único: o Modernismo. Basta citarmos Mário de Andrade e Oswald de Andrade, pesquisadores e assimiladores das novas técnicas que se desenvolviam numa Europa então revitalizada econômica e culturalmente. É o próprio Oswald que apelida Mário de futurista, embora este, como sabemos, renegue essa filiação. Não estamos interessados aqui em provar se Mário foi ou não futurista à Marinetti. Não podemos negar, entretanto, que seus poemas, principalmente os de seu segundo livro, Pauliceia desvairada, estão repletos das palavras em liberdade, da efervescência do mundo moderno e do progresso que Marinetti tanto idolatrava.

Podemos afirmar, pois, que é a partir do Futurismo que os poetas começam a se preocupar com a palavra em si mesma e a descobrir sua força no poema, gerando, como consequência, o desaparecimento do verso. Precisava-se, agora, pensar diferentemente o poema. Nunca, talvez, a linguagem poética tenha se afastado tanto da linguagem comum. Tudo o que de revolucionário surgiu depois para a poesia tem sua origem aí, na eleição de uma linguagem telegráfica vista como a única capaz de representar verdadeiramente uma humanidade bombardeada já pelos meios de comunicação. Das palavras em liberdade à destruição total do verso, com o Concretismo, não se passaram muitos anos. O processo foi rápido, passando, de certo modo, pela chamada poesia de 45 , onde, lado a lado com o uso tradicional do soneto, a palavra passa a ter um tratamento mais rebuscado, refinado. O gosto pela palavra rara foi retomado pela poesia de 45, juntamente com um racionalismo artesanal que procurava um lirismo enxuto, seco, impessoal, por mais paradoxal que isso possa parecer. Lirismo produzido por um intelecto que pesquisa sem cessar as formas de não poetizar o poema, como

4. CAMPOS, Haroldo de. Teoria da poesia concreta, p. 77-78. 
afirma João Cabral de Melo Neto em "Alguns toureiros", texto exemplar da busca de um poema sem poesia. ${ }^{5}$ Não é à toa que os concretistas retomam João Cabral como um de seus modelos. O poeta pernambucano já trazia em gérmen o que os poetas concretistas iriam desenvolver e radicalizar: a ausência do aspecto sentimental do poema, a busca de imagens o mais possível concretas, para, finalmente, abolindo de vez o verso tradicional, instituírem a palavra como elemento único capaz de trazer algo de novo a uma poesia para eles cansada e desgastada pelo tempo. O poema passa, com o concretismo, a ser um produto industrial, um objeto útil, trabalhado principalmente "para" e "pelo" olho. Sua função é, antes de tudo, ser visto, examinado, quase que passível de ser tocado ao instaurar sua forma no branco do papel. A palavra e suas possibilidades múltiplas. A palavra ajudada pela tecnologia moderna: tipos diferentes para ressaltar determinados aspectos, o uso da cor, o emprego de técnicas sofisticadas de diagramação, etc., eis o mundo dos concretos:

\section{PROGRAMA}

o POEMA CONCRETO aspira a ser: composição de elementos básicos da linguagem, organizados ótico-acusticamente no espaço gráfico por fatores de proximidade e semelhança, como uma espécie de ideograma para uma dada emoção, visando à apresentação direta - presentificação - do objeto.

a POESIA CONCRETA é a linguagem adequada à mente criativa contemporânea

permite a comunicação em seu grau + rápido

prefigura para o poema uma reintegração na vida cotidiana semelhante à q o BAUHAUS propiciou às artes visuais: quer como veículo de propaganda comercial (jornais, cartazes, TV, cinema, etc.), quer como objeto de pura fruição (funcionando na arquitetura, p. ex.), com campo de possibilidades análogo ao do objeto plástico substitui o mágico, o místico e o "maudit" pelo ÚTIL.

Nunca a literatura se identificou com o lúdico como nesse momento. Não um lúdico de cunho existencial, onde se questionam a essência e a aparência do mundo, mas o simples jogo de quebra-cabeças, onde quanto mais

5. MELO NETO. Antologia poética, p. 165-66

6. CAMPOS, Haroldo de. Teoria da poesia concreta, p. 48. 
matematicamente for utilizada a análise combinatória de palavras, sílabas ou fonemas, mais original se torna o poeta, mais deslumbrados se mostram leitores e críticos com os "achados" poéticos descobertos. Não queremos dizer que tudo não passou de uma simples brincadeira momentânea. Há poemas concretos que conseguiram se realizar, embora quase sempre em desacordo com o que os poeta-teóricos do movimento pregavam em seus programas-manifestos. Mas na grande maioria deles, o jogo da forma pela forma se esgota em pouco tempo. Essa falha talvez se deva à inexistência de um elemento transcendente, diríamos metafísico. Os concretistas esqueceram, como mostra Octavio Paz, que o que caracteriza o poema é "sua necessária dependência da palavra tanto como sua luta por transcendê-la". Preocupados em ir de encontro aos poetas chamados discursivos - confundindoos com os, e aí sim, superados "discurseiros", os concretistas não perceberam que "o discursivo, por si só, não encerra nem progresso nem decadência: constitui uma categoria instrumental". "Essa discursofobia levou-os a uma atitude bastante interessante: o que há de mais discursivo, retórico, empolado e muitas vezes "discurseiro" do que alguns dos textos teóricos concretistas? A esse teoricismo, Drummond replica:

Nunca vi tanto esforço de teoria para justificar essa nova forma de primitivismo, transformando pobreza imaginativa em rigor de criação. Consideram-se esgotadas as possibilidades da poesia, tal como esta foi realizada até agora, quando infinitos são os recursos da linguagem à disposição do verso, e um criador como Guimarães Rosa efetua, paralelamente, a revalorização contínua do vocabulário português. Por que os poetas não tentam um esforço nesse rumo?

Confesso o meu desinteresse pela onda concretista, que daqui a pouco rolará pelos estados, gerando um cacoete poético de fácil propagação. ${ }^{10}$

Para o Concretismo, o espírito contemporâneo é eminentemente antidiscursivo e objetivo por excelência. Por isso, a grande importância dada ao

7. PAZ. A consagração do instante, p. 52.

8. PORTELA. As perigosas curvas da vanguarda, p. 34 .

9. PORTELA. As perigosas curvas da vanguarda, p. 34.

10. ANDRADE. A moça e a angústia da poesia; páginas de diário, p. 9. 
ideograma chinês, representação condensada que "permite o máximo de economia e contenção, uma comunicação direta de formas verbais". ${ }^{11}$ Dessa maneira, ser discursivo, para os concretos, é, no seu momento presente, não ser um poeta de seu tempo. Mais ainda: no poema concreto a vida do autor é um elemento estranho e inadmissível por não passar de mera ambição romântica já há muito ultrapassada:

A poesia em vida - ambição romântica à qual não deixa de filiar-se esse misto de "capela literária, colégio espiritual, igreja e sociedade secreta" que, segundo Sartre, é o Surrealismo - é algo estranho ao poema e que, no seu extremo, acaba mesmo prescindindo dele. [...] Em lugar da poesia estado místico, da poesia ato mágico, das várias vivências para-poéticas, a poesia concreta supõe o poeta factivo, trabalhando rigorosamente sua obra (o poema objeto útil, de consumação), como um operário um muro, um arquiteto seu edifício. ${ }^{12}$

E é Décio Pignatari, um dos principais poetas do Concretismo, que afirma: "Um operário que trabalha uma peça ao torno não escreve nela o seu nome ou a sua revolta." ${ }^{13}$ No poema, como nessa peça ao torno, nada de pessoal deve existir. Nele deve-se perceber que a "vontade de construir superou a vontade de expressar ou de se expressar". ${ }^{14}$

\section{A palavra no verso}

A partir dos últimos anos da década de 60, o Concretismo começa a se esgotar. O que era tido como a única resposta à poesia, como a sua única verdade, descobriu-se corno "uma" resposta e "uma" possível verdade entre muitas outras. Que cada poeta escolhesse a sua. E, para mostrar que o verso não precisa ser destruído para que o poema exista, ou, que a palavra e sua força podem coexistir dentro do discurso, escolhemos um poeta que sempre se caracterizou

11. CAMPOS, Haroldo de. Teoria da poesia concreta, p. 96.

12. CAMPOS, Haroldo de. Teoria da poesia concreta, p. 103.

13. PIGNATARI. Teoria da poesia concreta, p. 125.

14. PIGNATARI. Teoria da poesia concreta, p. 125. 
por ser avesso a qualquer escola literária, um poeta desavergonhadamente lírico e romântico, um antípoda em face do Concretismo, de qualquer escola, de qualquer movimento de vanguarda: Mário Quintana. ${ }^{15}$

- Mas por que falar em poesia concretista? Diga-se "concretismo" apenas, e estará ressalvada a poesia. ( $\mathrm{CH}$, p. 97)

A minha escola poética? Não freqüento nenhuma. Fui sempre um gazeador de todas as escolas. Desde assinzinho... Tão bom! ( $\mathrm{CH}$, p. 42)

Sempre há uma vantagem em se ficar gagá: é que a gente diverte os amigos e parentes. Mas a melhor maneira de se sublimar a coisa é escrever festejadíssimos poemas para as revistas de vanguarda. (VH, p. 116-17)

Por que escolhemos Quintana? Porque, como os concretistas, teoriza sobre sua poesia a todo momento e porque o faz visceralmente diferente deles, seja de modo direto e explícito, como vemos no exemplo que se segue,

Quanto ao exercício da poesia, nem falar! Qualquer poeta sabe como dói, como é preciso virar a alma pelo avesso para fazer um verdadeiro poema - salvo se você for um poeta concretista, porque, na verdade, não há nada mais abstrato. ( $V H$, p. 22)

seja indiretamente, opondo à criação racional e objetiva um eminente predomínio do eu lírico:

Jamais deves buscar a coisa em si, a qual depende tão-somente dos espelhos.

A coisa em si, nunca: a coisa em ti.

Um pintor, por exemplo, não pinta uma arvore: ele pinta-se uma árvore.

E um grande poeta - espécie de rei Midas à sua maneira - um grande poeta, bem que ele poderia dizer:

- Tudo o que eu toco se transforma em mim. (CH, p. 58)

15. Os livros de Quintana, citados no corpo do trabalho, têm as seguintes siglas:

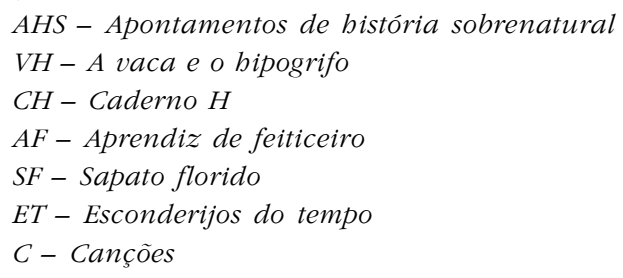


A todo instante - seja ao longo de seu trabalho cotidiano de jornalista junto ao Correio do Povo de Porto Alegre, ou através de seus próprios poemas, Quintana vai se referir à palavra e ao verso. Só que, para ele, ambos são verdadeiras fórmulas mágicas:

A beleza de um verso não está no que diz, mas no poder encantatório das palavras que diz: um verso é uma fórmula mágica. ( $\mathrm{CH}$, p. 59)

Eu te paguei minha pesada moeda,

Poesia...

Ó teus espelhos deformantes e límpidos

Como a água! Sim, desde menino,

Meus olhos se abriam insones como flores no escuro

Até que, longe, no horizonte, eu via

A Lua vindo, esbelta como um lirio...

Às vezes numa túnica de Infanta

Sonâmbula... Às vezes virginalmente nua...

E era branca como as nozes que os esquilos descascam na mata...

Pura como um punhal de sacrifício...

(Em meus lábios queimava-se, ignorada, a palavra mágica!) ( $A H S$, p. 89)

A força das palavras, para Quintana, está no poder encantatório que delas emana, poder esse que, constantemente buscado, desfaz-se irremediavelmente, pois o poeta é, antes de tudo, um ser humano obrigado a "lidar com a ingrata linguagem alheia... / A impura linguagem dos homens”. (AHS, p. 163)

Eu queria trazer-te uns versos muito lindos colhidos no mais íntimo de mim...

Suas palavras

seriam as mais simples do mundo,

porém não sei que luz as iluminaria

que terias de fechar teus olhos para as ouvir...

Sim! uma luz que viria de dentro delas, como essa que acende inesperadas cores nas lanternas chinesas de papel.

Trago-te palavras, apenas... e que estão escritas do lado de fora do papel... (AHS, p. 79)

Cada palavra é uma borboleta morta espetada na página: Por isso a palavra escrita é sempre triste... (AHS, p. 143) 
Poderíamos dizer, entretanto, que em certos·momentos Quintana se aproxima de uma atitude concretista. Não na identificação palavra/coisa ou na busca da própria estrutura do poema como seu conteúdo informativo, mas na eleição da palavra a fim de ressaltar-lhe as possibilidades fônico-silábicas, como mostra o seguinte exemplo:

Para as nossas cidades metálicas, que melhor ornamentação que os cactos? Se não por outros motivos, já bastava o seu próprio nome cacto - tão adequadamente cacofônico. ( $\mathrm{CH}$, p. 54)

Porém, não pensemos que Quintana, ao se voltar para a palavra em si, tenha os mesmos objetivos que os poetas concretistas tinham, isto é, uma simples tentativa de se alcançar (sejamos concretos por um momento) a verbivocovisualidade. Bastaria lermos alguns títulos de seus livros, para penetrarmos neste mundo mágico de sonho e encantamento que é sua poesia: Aprendiz de feiticeiro, Espelho mágico, A vaca e o hipogrifo, Apontamentos de história sobrenatural, Esconderijos do tempo. Para Quintana, a poesia é um mistério indecifrável, e no verso, a palavra tem uma força antes de tudo mágico-sugestiva:

E havia uma gramática que dizia assim:

"Substantivo (concreto) é tudo quanto indica

Pessoa, animal ou cousa: João, sabiá, caneta”.

Eu gosto é das cousas. As cousas, sim!..

As pessoas atrapalham. Estão em toda parte.

Multiplicam-se em excesso.

As cousas são quietas. Bastam-se. Não se metem com ninguém.

Uma pedra. Um armário. Um ovo. (Ovo, nem sempre,

Ovo pode estar choco: é inquietante...)

As cousas vivem metidas com as suas cousas.

E não exigem nada.

Apenas que não as tirem do lugar onde estão.

E João pode neste mesmo instante vir bater à nossa porta.

Para quê? Não importa: João, vem!

E há-de estar triste ou alegre, reticente ou falastrão,

Amigo ou adverso... João só será definitivo

Quando esticar a canela. Morre, João...

Mas o bom, mesmo, são os adjetivos,

Os puros adjetivos isentos de qualquer objeto. 
Verde. Macio. Áspero. Rente. Escuro. Luminoso.

Sonoro. Lento. Eu sonho

Com uma linguagem composta unicamente de adjetivos

Como decerto é a linguagem das plantas e dos animais.

Ainda mais:

Eu sonho com um poema

Cujas palavras sumarentas escorram

Como a polpa de um fruto maduro em tua boca,

Um poema que te mate de amor

Antes mesmo que tu lhe saibas o misterioso sentido:

Basta provares o seu gosto... (AHS, p. 100-101)

Aspecto fisiognômico, sim. Acústico também. Mas antes de tudo, magia verbal, encantamento, sonho, sugestão, sensações. Assim é que Quintana continua com suas mágicas palavras:

Com os seus OO de espanto, seus RR guturais, seu hirto H, HORROR é uma palavra de cabelos em pé, assustada de sua própria significação. (SF, p. 64)

\section{Camões}

Seu nome retorcido como um búzio

Nele sopra Netuno... (AHS, p. 140)

O nome Nabucodonosor é belo como um cortejo religioso. O triste é que seus súditos para abreviar, chamavam-no simplesmente de Bubu. ( $\mathrm{CH}$, p. 24)

Delícia de olhar, no céu, os v v v dos vôos distanciando-se... (VH, p. 130)

Entretanto, é com o poema "Anêmona" que vemos mais explicitamente o que temos dito até agora. Do verso sempre cultuado como algo que constantemente se renova, Quintana passa à palavra como elemento primordial na instauração da magia poética. Poesia e magia se confundem, e o ritual tem início, enredando poeta e leitor: 
Não é preciso um verso... nem

Uma oração...

Basta que digas a palavra anêmona

E tudo esquecerás, enredado na sua

Fantasmagórica palpitação. (AHS, p. 133)

O mesmo acontece com um trecho de Caderno H, chamado "Cântaro":

Na linguagem corrente não se encontra a palavra "Cântaro". Mas é uma palavra que jamais poderá sair dos poemas. Há palavras assim. São como esses nobres animais heráldicos, que só existem nos brasões. (CH, p. 168)

Os exemplos em que a poesia, o poema e a palavra poética assumem status mágico e revelador de um outro mundo recriado pela imaginação do poeta e do leitor são inúmeros em Quintana. Para ele, um poema é feito de mistério e deve falar por si mesmo através das palavras mágicas que o constroem. Um poema não é passível de explicações lógicas. Ele se explica no seu misterioso fascínio:

Um poema como um gole d'água bebido no escuro.

Como um pobre animal palpitando ferido.

Como pequenina moeda de prata perdida para sempre na floresta noturna. Um poema sem outra angústia que a sua misteriosa condição de poema.

Triste.

Solitário.

Único.

Ferido de mortal beleza. ( $A F$, p. 151-52)

Sonho, magia, encantamento: tudo isso inunda o poema e, nele, a palavra é também um elemento mágico-encantatório. Assim, o "nome sereno" da deusa Palas ecoa, misterioso e fantástico na sua leveza vocálica e sonora, dentro do estranho e envolvente poema "A noite".

A noite é uma enorme Esfinge de granito negro

Lá fora.

Eu acendo a minha lâmpada de cabeceira.

Estou lendo Sherlock Holmes.

Mas, nos ventres, há fetos pensativos desenvolvendo-se...

E há cabelos que estão crescendo, lentamente, por debaixo da terra, 
Junto com as raízes úmidas...

E há cânceres... cânceres!... distendendo-se como lentos dedos...

Impossível, meu caro doutor Watson, seguir o fio desta sua confusa e deliciosa história.

A Noite amassa pavor nas entrelinhas.

É um grude espesso, obscuro...

Vontade de gritar claros nomes serenos

Pallas Nausican Athena Ai, mas os deuses se foram...

Só tu aí ficaste...

Só tu, do fundo da noite imensa, a agonizares eternamente na tua cruz!...(AF, p.162-163)

Mais comum, mas nem por isso menos capaz de encantar poeta e leitor, é a palavra "miosótis", que ao ser pronunciada, cria o "triste encanto" do poema "Canção azul":

Triste, Poeta, triste a florzinha azul que sem querer pisaste no teu caminho... Miosótis, - disseste, inclinado um instante sobre ela.

E ela acabou de morrer, aos poucos, dentre a relva úmida.

Sem nunca ter sabido que se chamava miosótis.

Nem que iria impregnar, com o seu triste encanto,

O teu poema daquele dia... ( $C$, p. 34)

E, embora não se refira explicitamente à palavra como elemento mágico e encantatório, não são elas que, através das imagens que brotam do poema "Cântico" recriam o êxtase da possessão poética iminente?

O vento verga as árvores, o vento clamoroso da aurora...

Tu vens precedida pelos vôos altos,

Pela marcha lenta das nuvens.

Tu vens do mar, comandando as frotas do Descobrimento!

Minh'alma é trêmula da revoada dos Arcanjos.

Eu escancaro amplamente as janelas.

Tu vens montada no claro touro da aurora.

Os clarins de ouro dos teus cabelos cantam na luz! ( $A F$, p. 166)

O mesmo clima de encantamento e magia se produz no poema que se segue, quando Quintana se refere, aí explicitamente, aos versos que, no momento da leitura, revelam uma vida própria no seu "timbre diverso de silêncio": 
A beleza dos versos impressos em livro

- serena beleza com algo de eternidade -

Antes que venha conturbá-los a vOz das declamadoras.

Ali repousam eles, misteriosos cântaros,

Nas suas frágeis prateleiras de vidro...

Ali repousam eles, imóveis e silenciosos.

Mas não mudos e iguais como esses mortos em suas tumbas.

Têm, cada um, um timbre diverso de silêncio...

Só tua alma distingue seus diferentes passos,

Quando o único rumor em teu quarto

É quando voltas, de alma suspensa - mais uma página

Do livro... Mas um verso fere o teu peito como a espada de um anjo.

E ficas, como se tivesses feito, sem querer, um milagre...

Oh! que revoada, que revoada de asas! ( $A H S$, p. 4)

Mesmo quando Quintana desmembra a palavra para dar a ela um novo significado, atitude tão comum no concretismo, o faz com o intuito de ressaltarlhe a oculta face mágica. Daí um único verso ser capaz de trazer em si todo o universo, pois é um uni-verso:

"Treme a folha no galho mais alto" - escrevo. Paro e sorvo, de olhos fechados, o cheiro bom da terra, do capim chovido... Parece que quer vir um poema... Abro os olhos e fico olhando, interrogativamente, a linha que escrevi no alto da página. Depois de longo instante, acrescentolhe três pontinhos. Assim não ficará tão só enquanto aguarda as companheiras. O vento fareja-me a face como um cachorro. Eu farejo o poema. Ah, todo o mundo sabe que a poesia está em toda parte, mas agora cabe toda ela na folha que treme.

Por que não caberia então em um único verso? Um uni-verso?

Treme a folha no galho mais alto.

(O resto é paisagem...) ( $\mathrm{CH}$, p. 104)

E, quando cria palavras (uma única vez em toda a sua obra publicada em livro) o resultado é o de sempre: dentro do verso, a palavra pode ser a chave mágica para a descoberta de um outro mundo, de um intermundo:

O bom do sono é mesmo o sonomar

O sono de alto mar sem terra à vista

Onde és como um barco sem barqueiro 
Cujo rumo é traçado pelo ar...

Mas no fundo do mar só tem vasos barrocos!

Viste? Água não tem e não tem sol nem lua

E essa luz, que parece que flutua,

É a mesma dos lampiões de acetileno

Daquela antiga, pequenina rua...

Mortos? Nenhum... Nem vivos... Eles são

Habitantes de um trêmulo intermundo

E nunca se detêm mais que um segundo

Ante o parado olhar dos escafandros.

E onde o relógio é um animal estranho

Incompreensível e sem nome algum

E o tempo ondeia sem medida exata

E onde nada se encontra e tudo se acha,

Por que é que vieste - intruso - devassar

Essas formas e faces e esse mundo

Onde o enigma és tu?

\section{Retorna, irmão:}

O bom do sono é mesmo o sonomar! (AHS, p. 119)

O próprio jogo entre palavras homônimas projeta no poema o misterioso fascínio da poesia que, para Quintana, se identifica com a Vida:

Comecei a escrever este poema às $12 \mathrm{~h} 23 \mathrm{~min}$ de 12 de agosto de 1974

Os pesquisadores não querem outra vida

Eles morrem por dados

- mal sabem que a vida é um incerto e implacável jogo de dados...

E eu que tanto desejava que minha biografia

terminasse de súbito

simplesmente assim:

"Desaparecido na batalha de Itororó"!

(Desaparecido? Meu Deus, quem sabe se ainda estou vivo?!) (VH, p. 111)

O racionalismo crítico procura reduzir o poema a fórmulas. Entretanto, os "dados" que críticos e pesquisadores manipulam tão racionalmente não são os mesmos com os quais a vida joga seu jogo. A pretensa certeza estatística dos primeiros se desfaz em face do mistério e do inesperado que os últimos revelam.

Como vemos, Quintana não vê a palavra como quer Augusto de Campos, um dos poeta-teóricos do concretismo, isto é: 
[...] em si mesma - campo magnético de possibilidades - como um objeto dinâmico, uma célula viva, um organismo completo, com propriedades psico-físico-químicas tacto antenas circulação coração: viva. ${ }^{16}$

Pelo contrário, ela estará sempre dentro do verso, guardando, porém, uma vida própria capaz de criar na mente do leitor imagens de todos os tipos, sempre reveladoras de um elemento subjetivo, lírico por excelência. A própria "nomeação", ato tão cultuado pelos concretistas (nomear um objeto é presentificálo no poema) assume em Quintana uma nova-antiga nuance: nomear é dominar o outro, nomear é um ato mágico, é a própria criação:

As coisas que não têm nome assustam, escravizam-nos, devoramnos... Se a bela faz de ti gato e sapato, chama-lhe, por exemplo, A BELA DESDENHOSA. E ei-la rotulada, classificada, exorcismada, simples marionete, agora com todos os gestos perfeitamente previsíveis, dentro do seu papel de boneca de pau. E no dia em que chamares a um dragão de JOLI, o dragão te seguirá por toda parte como um cachorrinho... (SF, p. 74)

E se as coisas que não têm nome assustam, como diz Quintana, por que seu próprio nome, pronunciado por um anjo, instaura um clima estranho e obscuro? Porque para o poeta o "nome" nem sempre limita o objeto a que se refere; pelo contrário, pode revelar o mundo interior de quem o porta, pode despertar esse ser para o verdadeiro eu que se esconde por detrás de simples aparências:

Na volta da escada,

$\mathrm{Na}$ volta escura da escada

O Anjo disse o meu nome.

E o meu nome varou de lado a lado o meu peito.

E vinha um rumor distante de vozes clamando clamando...

Deixa-me!

Que tenho a ver com as tuas naus perdidas?

Deixa-me sozinho com os meus pássaros... com os meus caminhos.. com as minhas nuvens... (AF, p. 153-54)

Ainda em relação ao "nomear", Décio Pignatari afirma o seguinte:

16. CAMPOS, Augusto de. Teoria da poesia concreta, p.44. 
a poesia concreta realiza a síntese crítica, isomórfica: \jarro\é a palavra jarro e também jarro mesmo enquanto conteúdo, isto é, enquanto objeto designado. a palavra jarro é a coisa da coisa, o jarro do jarro, como \$la mer dans la merl. isomorfismo.

a poesia concreta acaba com o símbolo, o mito. com o mistério. o mais lúcido trabalho intelectual para a intuição mais clara. acabar com as alusões. com os formalismos nirvânicos da poesia pura. a beleza ativa, não para a contemplação. para nutrir o impulso, pound. no máximo: ser raro e claro, como disse o último fernando pessoa. criar problemas justos e resolvê-los em termos de linguagem sensível. ${ }^{17}$

Nada mais oposto à posição de Mário Quintana do que esta afirmativa. Parodiando Gertrude Stein, Quintana nos mostra que "uma rosa - num poema - é sempre a primeira rosa" ( $V H$, p.88) Dizer "rosa" em um poema não é trazer para dentro dele simplesmente o objeto designado, mas sim todo um mundo de beleza e encantamento. É revitalizar o símbolo e o mito, e não destruí-los. É inundar o poema de mistério, de alusões, de beleza contemplada e revificada pela imaginação que a primeira rosa em nós imprimiu. A palavra "rosa" deixa, em Quintana, de ser, como disse Décio Pignatari em relação à palavra "jarro", "a coisa da coisa”, para passar a ser "a coisa de uma outra coisa". Quintana não quer "criar problemas justos para resolvêlos em termos de linguagem sensível". Seu objetivo é, poderíamos dizer, deixar que uma imaginação sensível busque recriá-los sem jamais resolvê-los. Suas palavras são, como ele próprio afirma, loucas. Quintana não possui nada do poeta factivo e racional; o poeta nada mais é do que o instrumento de algo que desconhece:

Impossível fazer um poema

neste momento.

Não, minha filha, eu não sou a música

- sou o instrumento.

Sou, talvez, dessas máscaras ocas

num arruinado monumento:

empresto palavras loucas

à voz dispersa do vento... ( $A H S$, p. 34)

17. PIGNATARI. Teoria da poesia concreta, p. 41. 
Mesmo quando Quintana se refere ao poema como "uma fórmula algébrica" nada há nele do matemático racionalismo concretista. Essa fórmula algébrica se apresenta ao poeta e ao leitor como um mundo indecifrável, estranho, repleto de signos, poderíamos dizer, esotéricos, por revelarem o mistério de um mundo para sempre submerso e devorado pelas palavras que o compõem. Um ser que palpita e vive de seu mistério, de seus enigmas, o poema tem nas palavras sua razão de existir na sua des-razão de sonho e magia:

As palavras espiam como animais:

umas rajadas, sensuais, que nem panteras...

outras, escuras, furtivas raposas...

mas as mais belas palavras estão pousadas nas frondes mais altas, como pássaros...

O poema está parado em meio da clareira.

O poema

caiu

na armadilha! debate-se

e ora subdivide-se e entrechoca-se como esferas de vidro colorido

ora é uma fórmula algébrica

ora, como um sexo, palpita... Que importa

que importa qual seja enfim o seu verdadeiro universo?

Ele em breve será inteiramente devorado pelas palavras. (ET, p. 71)

$\mathrm{E}$, finalmente, para quem diz, como os poetas concretistas, que a poesia lírica e subjetiva, baseada na linguagem discursiva revelada através do também tradicional verso não passava de coisa morta e ultrapassada, para esses poetas que não desmerecemos, pois revelaram uma penetrante consciência de que o fazer poético poderia se atualizar em novas formas sugeridas por um mundo novo que surgia e que até hoje revoluciona a tudo e a todos, mas que às vezes infantilmente radicalizaram sua posição, Mário Quintana, o poeta que escolhemos por ser moderno ao falar da atemporalidade das interrogações do homem e do criador, deixa em seu último livro, Esconderijo do tempo, a visão de que a poesia, quando verdadeira, sempre foi, é e será renovação, sem precisar se preocupar com artifícios e modismos passageiros: 
Quem disse que a poesia é apenas agreste avena?

A poesia é a eterna Tomada da Bastilha

o eterno quebra-quebra

o enforcar de judas, executivos e catedráticos em todas as esquinas

e,

a um ruflar poderoso de asas,

entre cortinas incendiadas,

os Anjos do Senhor estuprando as mais belas filhas dos mortais...

Deles, nascem os poetas.

Não todos... Os legítimos

espúrios:

um Rimbaud, um Pöe, um Cruz e Souza...

(Rege-os, misteriosamente, o décimo-terceiro signo do Zodíaco.)

(ET, p. 95)

\section{Mário Quintana: verse as the magical power of words}

Abstract: This article aims at discussing the specificity of Mário Quintana's aesthetic project in relation to the avant-garde currents of Brazilian poetry in his time, especially Concretism, so as to underscore the lyrical modernity of his poetry.

Keywords: Brazilian poetry, concretism, Mário Quintana.

$$
\text { Referências }
$$

ANDRADE, Carlos Drummond de. A moça e a angústia da poesia; páginas de diário. Jornal do Brasil, Rio de Janeiro, 28 out. 1980. Caderno B, p. 9.

BREMOND, Henri. La poésie pure. Paris: Bernard Grass, 1937.

CAMPOS, Augusto de; PIGNATARI, Décio; CAMPOS, Haroldo de. Teoria da poesia concreta. São Paulo: Duas Cidades, 1975.

MELO NETO, João Cabral de. Antologia poética. Rio de Janeiro: Sabiá, 1967.

NOVALIS. Fragments. Paris: Aubier Montaigne, 1973.

PAZ, Octavio. A consagração do instante. In: Signos em rotação. São Paulo: Perspectiva, 1972. 
PLATÃO. Ion. In: Oeuvres complètes. Paris: Gallimard, 1950.

PORTELA, Eduardo. As perigosas curvas da vanguarda. In: Vanguarda e cultura de massa. Rio de Janeiro: Tempo Brasileiro, 1978.

QUINTANA, Mário. A rua dos cataventos (1940); Canções (1946); Sapato florido (1948); Aprendiz de feiticeiro (1950); Espelho mágico (1951). In: Poesias. Porto Alegre: Globo, 1975.

QUINTANA, Mário. A vaca e o hipogrifo. Porto Alegre: Garatuja, 1977.

QUINTANA, Mário. Apontamentos de bistória sobrenatural. Porto Alegre: Globo, 1976.

QUINTANA, Mário. Caderno H. Porto Alegre: Globo, 1973.

QUINTANA, Mário. Esconderijo do tempo. Porto Alegre: L\&PM, 1980. 